\title{
Uniqueness of abrupt visual onset in capturing attention
}

\author{
JOHN JONIDES \\ University of Michigan, Ann Arbor, Michigan \\ and \\ STEVEN YANTIS \\ Johns Hopkins University, Baltimore, Maryland
}

\begin{abstract}
Yantis and Jonides (1984) demonstrated that the detection of a target in visual search was markedly enhanced when the target was presented as an abruptly onset character embedded among other characters whose presentation was not characterized by abrupt onset. This effect was attributed to a shift of attention caused by abrupt onset. In the present article, we report experiments investigating whether abrupt onset is simply one member of a large class of stimulus characteristics, all of which are capable of capturing attention. To test this possibility, we compared abrupt onset with differences in stimulus luminance and hue to determine whether these also could elicit shifts of attention. They could not.
\end{abstract}

In tasks requiring visual search, stimuli with abrupt onsets evidently capture attentional resources (Yantis \& Jonides, 1984). In that earlier work, we demonstrated this by employing multiple-item displays that contained one item with an abrupt onset (the onset item) embedded among several other items presented by removing camouflage from figures stationed at various locations in the display (the no-onset items). When the onset item was the target of visual search, variations in the number of no-onset items in the array caused the reaction time required to detect the target to vary by less than $8 \mathrm{msec}$ per item. By contrast, when the target was itself a no-onset item and one of the distractors had an abrupt onset, an increase in the number of no-onset items in the field caused an increase in reaction time of more than $24 \mathrm{msec}$ per item.

The model we proposed to account for this effect was based on the notion that abrupt onset captures visual attention. According to this model, if there is a single onset item in a display, attention shifts to it first and stimulus analysis proceeds for this item. If it is the target, processing ceases and a positive detection response is initiated. If it is not the target, processing continues serially for the other items of the display until a target is identified or until analysis of the display is complete. The critical feature of this model is that abrupt onset exerts control over the allocation of attention such that it draws attention to its location. This was reflected in our visual search task by the severe attenuation of the display-size effect when the target had an abrupt onset.

We thank Joanne Alexander for her valuable help in data collection and analysis. This research was supported by Grant 82-0297 from the Air Force Office of Scientific Research to John Jonides. Address requests for reprints to John Jonides, Department of Psychology, University of Michigan, 330 Packard Road, Ann Arbor, MI 48104.
One could argue, however, that any noticeable difference between stimuli, whether due to abrupt onset or to some other distinguishing feature, could produce the same attentional capture effect. For example, research on visual search has revealed that clear stimulus differences on the dimensions of color or shape can produce search performance in which accuracy and time to detect a target are independent of the number of items to be searched (e.g., Donderi \& Zelnicker, 1969; Egeth, Jonides, \& Wall, 1972; Francolini \& Egeth, 1980; Treisman \& Gelade, 1980). This pattern of results could come about if the discrepant item (e.g., a red letter embedded among black ones) immediately captured attention in much the same way that an item with an abrupt onset immediately captures attention if the other items in a display do not have abrupt onsets. Will any highly salient stimulus difference cause a shift of attention as do abrupt onsets? This is the question that motivated the present experiments.

Experiment 1 compared the efficiency of attentional capture with three different stimulus sets. The first had an onset item embedded in no-onset items, as studied by Yantis and Jonides (1984). The second stimulus set included a bright item embedded among dim items. The third involved a red item embedded among green ones (and vice versa).

We know from the work of Treisman and her colleagues (e.g., Treisman \& Gelade, 1980) that when subjects must detect a target that is reliably distinguishable from nontargets on the basis of a simple visual feature, such as color, such detection can take place without interference from nontarget items. Treisman's research reveals that certain stimulus features may be used as a basis for selection "preattentively." For example, color, texture, and certain of the Gestalt features (e.g., closure) have been identified as being preattentively available (Bergen \& 
Julesz, 1983; Kahneman \& Henik, 1981; Treisman \& Gelade, 1980). So the issue is not whether subjects are able to selectively attend to a certain item in a display on the basis of one of these features. Previous research has demonstrated that they are. Rather, we ask whether such features force attention to an item that has no higher probability of being the target than any other item in a display.

Our purpose in the first experiment was to determine whether attentional capture by abrupt onset was simply a consequence of the fact that the onset item was unique among the no-onset items in the experiments of Yantis and Jonides (1984). If it is only stimulus uniqueness that produces capture, and not abrupt onset per se, then the theoretical implications of attentional capture by abrupt onset would require modification. For example, it may have nothing to do with the difference between channels putatively specialized for processing transient versus sustained stimuli, as some investigators have speculated (Breitmeyer \& Ganz, 1976; Todd \& Van Gelder, 1979; Yantis \& Jonides, 1984).

\section{EXPERIMENT 1}

\section{Method}

Subjects. Thirty-six University of Michigan students were paid to participate in one 50-min session. All had uncorrected normal vision. Each subject was assigned randomly to one of the three main between-subjects conditions: 11 were assigned to the onset condition, 9 to the intensity condition, and 16 to the color condition. The color condition had two subgroups of 8 subjects each; the color of the unique item differed (red or green) for these subgroups.

Apparatus. For the onset and the intensity conditions, the stimulus events were controlled and the responses collected by a Digital Equipment Corporation (DEC) PDP-11/60 computer. The stimulus events appeared on a DEC VT-11 graphics scope with a P4 phosphor. The subjects responded by pressing keys on a Hewlett-Packard $2621 \mathrm{~A}$ terminal keyboard while sitting in a sound-attenuating booth under comfortable illumination. For the color condition, a DEC LSI-11/23 + computer controlled the stimulus events and collected the responses. A Seiko Model GR-1104 color graphics terminal displayed the stimuli.

Stimuli. The letters were constructed by illuminating five of the seven segments of a block figure eight (similar to the number 8 that appears on the display of a digital clock; see Yantis \& Jonides, 1984 , Figure 3, for examples). The letters had a visual angle of $1.9^{\circ}$ in height and $1^{\circ}$ in width from a viewing distance of $45 \mathrm{~cm}$. The population of letters was $\mathrm{E}, \mathrm{H}, \mathrm{P}, \mathrm{S}$, and $\mathrm{U}$. The letters were situated $5.7^{\circ}$ from fixation at the vertices of an imaginary hexagon with sides of $5.7^{\circ}$.

The stimulus letters were designed so that they could serve as either "onset" or "no-onset" stimuli (Todd \& Van Gelder, 1979). The onset stimuli were five-segment letters appearing in previously blank locations. The no-onset stimuli were presented as follows: A block figure eight, consisting of all seven segments used to construct the letters, was displayed for $1,000 \mathrm{msec}$ before the no-onset letter was to appear. At the end of the 1,000-msec preview period, two of the seven segments were extinguished, revealing a letter. One way of viewing this presentation mode is that the letter itself was present, but camouflaged, for $1,000 \mathrm{msec}$ before the camouflage was removed.

Design. Three between-subjects conditions were used. In the onset condition, the unique item had an abrupt onset and the other items were of the camouflage-removal (no-onset) type. In the intensity condition, the unique item was relatively bright, whereas the other items were at the baseline display intensity. In the color condition, the unique item was of one color and the remaining items were of another color (red among green for half the subjects in this condition, and green among red for the other half).

The same design was used in each of the three between-subjects conditions. The design was as follows: Two display sizes, 2 and 4 items, were crossed with three types of trials-target present and unique, target present and not unique, and target absent. Overall, the target was present on half the trials and absent on the remaining trials. When the target was present, it was unique on half its appearances for Display Size 2 and on one-quarter of its appearances for Display Size 4. This was in contrast to the design (and goals) of Treisman and Gelade (1980), who also used targets and distractors that differed with respect to a simple visual feature (e.g. , color). In their experiments involving disjunctive search, the unique item was always, by definition, the target. In the present experiment, the physical distinction between the unique and the nonunique items was uncorrelated with the target/distractor distinction. The possible strategy of intentionally attending to the unique item was therefore rendered ineffective.

A session consisted of six blocks of 64 trials each. Within each block, to reiterate, there were 32 target-absent trials (16 each with Display Sizes 2 and 4) and 32 target-present trials. The target-present trials were distributed as follows: 8 Display Size 2 and target unique, 8 Display Size 2 and target not unique, 4 Display Size 4 and target unique, and 12 Display Size 4 and target not unique. The order of trial types was randomly permuted in each block.

Procedure. The trial events in the onset condition were very similar to those in Experiment 3 of Yantis and Jonides (1984). Each trial began with a 1,000 -msec presentation of a target letter in the center of the screen. This was followed by the presentation of three block figure eights placed at the vertices of an imaginary, upwardpointing or (on alternate trials) downward-pointing triangle (i.e., at three of the vertices of the imaginary hexagon used for stimulus placement). After 1,000 msec, the figure eights were replaced by the test display. One letter appeared in what had been a blank location (the onset letter) and, simultaneously, a subset of the figureeight segments was removed (no-onset letters).

Segment removal for the no-onset letters proceeded as follows. On Display Size 2 trials, two figure eights disappeared completely, and two segments of the third disappeared, revealing a letter at that location. On Display Size 4 trials, two segments in each of the three figure eights disappeared, revealing three letters. On each trial of the onset condition, then, there was always one onset letter and either one or three no-onset letters. On Display Size 2 trials, the onset and no-onset letters were always diametrically opposite. Recall that the target was the onset letter on $1 / n$ of the trials (where $n$ is the display size), and it was one of the no-onset letters on the remaining trials.

The procedure for the intensity and color conditions was as follows: a white target letter appeared in the center of the screen for $1,000 \mathrm{msec}$. It was extinguished and replaced by the test display, which consisted of either two or four block letters situated at a subset of the vertices of the imaginary hexagon. All of these letters appeared simultaneously and abruptly; no figure-eight premasks were used in these conditions. In the intensity condition, one letter was bright $\left(42.3 \mathrm{~cd} / \mathrm{m}^{2}\right)$ and the rest were relatively $\operatorname{dim}\left(7.1 \mathrm{~cd} / \mathrm{m}^{2}\right)$. In the color condition, one letter was of one color and the rest were of the other (red vs. green or vice versa).

In all three main conditions, the subjects were told to search visually for the target, and to press one key on the keyboard with the right index finger if the target was present and another key with the left index finger if the target was absent. They were told that the figure eights (or the intensities or colors of the letters) were 
Table 1

Error Rates (Percent) by Condition, Trial Type, and Display Size (2 or 4): Experiment 1

\begin{tabular}{|c|c|c|c|c|c|c|}
\hline \multirow[b]{2}{*}{ Condition } & \multicolumn{2}{|c|}{$\begin{array}{l}\text { Present- } \\
\text { Unique }\end{array}$} & \multicolumn{2}{|c|}{$\begin{array}{c}\text { Present- } \\
\text { Nonunique }\end{array}$} & \multicolumn{2}{|c|}{ Absent } \\
\hline & 2 & 4 & 2 & 4 & 2 & 4 \\
\hline Onset/No-onset & 2.4 & 4.9 & 5.4 & 6.7 & 3.7 & 2.9 \\
\hline Intensity & 6.2 & 6.6 & 3.2 & 5.9 & 3.2 & 4.1 \\
\hline Color* & 6.3 & 6.1 & 5.3 & 7.4 & 4.0 & 3.7 \\
\hline
\end{tabular}

*Red and green conditions combined.

irrelevant to the task, and that they should ignore this featural difference. As in Yantis and Jonides (1984), none of the subjects noticed the onset/no-onset distinction; on the other hand, all of the subjects noticed the intensity and the color differences. The subjects were instructed to respond as quickly as possible while maintaining accuracy.

\section{Results}

The reaction times (RTs) for the three conditions are plotted in Figure 1, Panels A through C. The corresponding error rates appear in Table 1 . The data for the two versions of the color condition (red among green and vice versa) have been combined since there were no significant differences between these two versions, as corroborated by the analyses presented below.

Separate analyses of variance were performed on the three main conditions (a significance level of $p<.05$ is used for all analyses unless otherwise noted). All analyses included the factors of trial type (present-unique, present-nonunique, and absent) and display size (2 and 4).

For the onset condition (Figure 1A), there were reliable effects of both trial type and display size $[F(2,20)=30.0$ and $F(1,10)=31.9$, respectively]. In addition, there was a reliable interaction between the variables $[F(2,20)=8.4]$. This interaction indicates that there is a difference arnong the slopes of the three trial-type functions. The slope for the present-onset condition was 0.5 msec per comparison, whereas that for the present-no-onset condition was $11.0 \mathrm{msec}$ per comparison, a significant difference $[t(10)$ $=2.7, p<.05]$. This distinctive pattern of results reflects attentional capture by the onset item (Yantis \& Jonides, 1984). Below, we fit a quantitative model to the functions in support of this conclusion.

An analysis of data from the intensity condition (Figure 1B) also revealed a significant main effect of both factors [trial type, $F(2,14)=32.7$; display size, $F(1,7)$ $=92.2 \mathrm{]}$. The interaction between them, however, was not significant $[F(2,14)<1]$. Here, the present-bright function and the present-dim function are roughly superimposed, a result reflecting no differential effect of target intensity upon visual attention. This is confirmed by the lack of a statistically significant difference between the slopes of these functions $[t(8)=0.04]$.

Finally, the analysis of data from the color condition (Figure 1C) included the between-subjects factor of unique color (red or green) and the within-subjects factors of trial type and display size. There were no main effects or interactions involving unique color (all $F_{\mathrm{s}}<1$ ). The trial type and display size variables both yielded significant effects $[F(2,14)=70.9$ and $F(1,7)=58.8$, respectively]. The only interaction to reach significance was that between trial type and display size $[F(2,14)=$ 5.2]. Again, the slopes of the unique color function and the nonunique color function are not significantly different $[t(15)=1.28]$, reflecting a failure of the unique item to capture visual attention.

The error rates in all three conditions were quite low, as indicated in Table 1. Within each condition, error rates generally increased with display size, as would be expected if the subjects were not trading speed for accuracy. There appears to be a slight bias toward negative responses, as revealed by a somewhat lower error rate
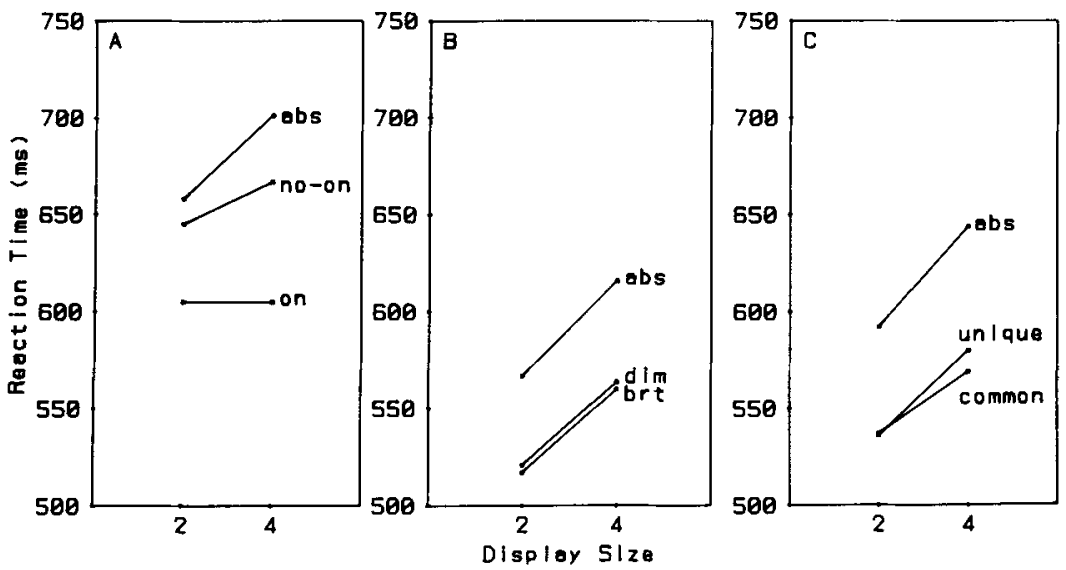

Figure 1. Mean reaction time for present-unique, present-nonunique, and absent trials of Experiment 1 as a function of display size in the onset (Panel $\mathbf{A}$ ), intensity (Panel B), and color (Panel C) conditions. on = present-onset; no-on = present - no-onset; abs = absent; brt $=$ present-bright; dim $=$ present - dim; common $=$ present-common color; unique $=$ present-unique color. 
for the absent conditions. Otherwise, the error rates are consistent with the RT results reported above.

\section{Discussion}

In order to provide an account of the RT effects shown in Figure 1, we selected two of the models tested by Yantis and Jonides (1984) and fit them to the data using multiple regression techniques. The first of these models (the capture model) is based on the assumption that a unique item in the visual field captures attention. This model accounted well for the onset data of Yantis and Jonides. The capture model (described in full by Yantis \& Jonides, 1984) asserts that search is sequential through the items in an array, terminating when a target is identified, with the constraint that a unique item is always examined first. The capture model may be contrasted with a serial selfterminating (SST) search model. According to the SST model, search proceeds in series from one item to another in a display until a target is found, or until every item has been examined. The unique item in each display receives treatment that is no different from that of any other item. Both models involve three parameters: a baseRT parameter, a per-item scan parameter, and a "fastpositive" parameter. For further details, see Yantis and Jonides (1984).

Table 2 shows a test of the capture and SST models for the present data. Listed are the observed and predicted response times for the various types of trials under the three experimental conditions. The predictions of the two models are shown under the headings "Capture" and "SST," respectively. The proportions of variance accounted for by the capture model are $97.5 \%, 72.0 \%$, and $74.1 \%$ for the onset, intensity, and color conditions, respectively. Plainly, the capture model provides a good account of the onset data and a poor account of the data from the intensity and color conditions.

The pattern of fits under the SST model is exactly the reverse of that under the capture model: The proportions of variance accounted for are $60.2 \%, 96.3 \%$, and $98.1 \%$ for the onset, intensity, and color conditions, respectively. The SST model fails to account well for the onset data, but it is a good representation of the intensity and color data.

On the basis of these model fits, we conclude that the onset condition differs in a fundamental way from the other two in the nature of the processing that is performed to detect a target. As we have previously demonstrated, abrupt onset leads to attentional capture - the onset item is examined first, with other items being examined in turn should the onset item not be the target. By contrast, a unique item that is saliently defined by a difference in either brightness or color is conferred no different status than any other item in a visual search display.

Two properties of Experiment 1 constrain this conclusion, however. First, the smaller of our display sizes-2 items-somewhat compromises the "uniqueness" of the unique item. In the intensity condition, for instance, only one item was ever bright, but it could not be considered truly unique in a display of one bright and one dim item. Second, the SST model that provided excellent fits to the intensity and color data was not given the best opportunity to fail in our experiment because of our inclusion of only two small display sizes.

These problems were addressed in Experiment 2, which incuded display sizes of 3,5 , and 7 items. This experiment allowed us to examine the predicted linearity of the display-size functions, while avoiding the problematic Display Size 2. Furthermore, it afforded us the opportunity to examine an anomaly in the data of Experiment 1: The overall mean RT in the onset condition $(658 \mathrm{msec})$ of Experiment 1 was longer than in the other two conditions (592 and $587 \mathrm{msec}$ for the intensity and color conditions, respectively) $[t(18)=1.83, .1>p>.05$ for onset vs. intensity and $t(25)=2.90$ for onset vs. color]. Although we do not believe these differences are of theoretical importance, we pursued them further in Experiment 2.

\section{EXPERIMENT 2}

\section{Method}

Subjects. Twenty-four University of Michigan students participated in the experiment, with 8 randomly assigned to each of the

Table 2

Observed and Predicted Mean Reaction Times for Capture and SST Models: Experiment 1

\begin{tabular}{|c|c|c|c|c|c|c|c|c|c|c|}
\hline \multirow[b]{3}{*}{ Trial Type } & \multirow{3}{*}{$\begin{array}{c}\text { Display } \\
\text { Size }\end{array}$} & \multicolumn{3}{|c|}{ Onset Condition } & \multicolumn{3}{|c|}{ Intensity Condition } & \multicolumn{3}{|c|}{ Color Condition* } \\
\hline & & \multirow[b]{2}{*}{ Observed } & \multicolumn{2}{|c|}{ Predicted } & \multirow[b]{2}{*}{ Observed } & \multicolumn{2}{|c|}{ Predicted } & \multirow[b]{2}{*}{ Observed } & \multicolumn{2}{|c|}{ Predicted } \\
\hline & & & Capture & SST & & Capture & SST & & Capture & SST \\
\hline Present-Unique & $\begin{array}{l}2 \\
4\end{array}$ & $\begin{array}{l}605 \\
606\end{array}$ & $\begin{array}{l}610 \\
610\end{array}$ & $\begin{array}{l}621 \\
639\end{array}$ & $\begin{array}{l}517 \\
560\end{array}$ & $\begin{array}{l}528 \\
528\end{array}$ & $\begin{array}{l}525 \\
556\end{array}$ & $\begin{array}{l}536 \\
580\end{array}$ & $\begin{array}{l}545 \\
545\end{array}$ & $\begin{array}{l}540 \\
570\end{array}$ \\
\hline Present-Nonunique & $\begin{array}{l}2 \\
4\end{array}$ & $\begin{array}{l}645 \\
667\end{array}$ & $\begin{array}{l}637 \\
664\end{array}$ & $\begin{array}{l}621 \\
639\end{array}$ & $\begin{array}{l}521 \\
564\end{array}$ & $\begin{array}{l}544 \\
560\end{array}$ & $\begin{array}{l}525 \\
556\end{array}$ & $\begin{array}{l}537 \\
569\end{array}$ & $\begin{array}{l}558 \\
571\end{array}$ & $\begin{array}{l}540 \\
570\end{array}$ \\
\hline Absent & $\begin{array}{l}2 \\
4\end{array}$ & $\begin{array}{l}658 \\
701\end{array}$ & $\begin{array}{l}652 \\
706\end{array}$ & $\begin{array}{l}661 \\
697\end{array}$ & $\begin{array}{l}567 \\
616\end{array}$ & $\begin{array}{l}575 \\
607\end{array}$ & $\begin{array}{l}560 \\
622\end{array}$ & $\begin{array}{l}592 \\
644\end{array}$ & $\begin{array}{l}605 \\
630\end{array}$ & $\begin{array}{l}588 \\
648\end{array}$ \\
\hline $\begin{array}{l}\text { Percent Variance } \\
\text { Accounted For }\end{array}$ & & & 97 & 60 & & 72 & 96 & & 74 & 98 \\
\hline
\end{tabular}

*Red and green conditions combined. 
Table 3

Number of Trials per Block of Each Trial Type in Experiment 2

\begin{tabular}{lrrrr}
\hline & \multicolumn{3}{c}{ Display Size } & \\
\cline { 2 - 4 } \multicolumn{1}{c}{ Trial Type } & 3 & 5 & 7 & Total \\
\hline Present-Unique & 5 & 3 & 2 & 10 \\
Present-Nonunique & 10 & 12 & 12 & 34 \\
Absent & 15 & 15 & 14 & 44 \\
Total & 30 & 30 & 28 & 88 \\
\hline
\end{tabular}

onset, intensity, and color conditions, respectively. All had normal or corrected-to-normal vision.

Apparatus and Stimuli. The apparatus was identical to that used in Experiment 1. The letters $C, F$, and $L$ were added to the stimulus set used in Experiment 1 to provide a sufficient number of letters for the larger display sizes.

Design. The design of this experiment was virtually identical to that of Experiment 1. Again, there were three between-subjects conditions, with the unique item defined by its onset, its intensity, or its color. Because we found no difference between the counterbalanced versions of the color condition in Experiment 1, we included only one version in Experiment 2, with a red item always embedded among green ones.

For each condition, there were three display sizes: 3,5 , or 7 items. As in Experiment 1, there were also three types of trials: those with the target present and unique, those with the target present and not unique, and those with the target absent. One of the display items was unique on all trials, so the presence of a unique item did not indicate whether a target was present in a display.

The target was present on half of the trials of each condition and absent on the other half. When the target was present, it was unique on one-third of its appearances with Display Size 3, on one-fifth of its appearances with Display Size 5, and on one-seventh of its appearances with Display Size 7. Therefore, as in the previous experiment, the unique item in each display was the target on only a chance proportion of the trials.

A session consisted of six blocks of 88 trials each. The number of trials per block of each trial type is shown in Table 3. Two constraints guided our choice of trial distribution. First, equal numbers of target-present and target-absent trials under each display target had to be unique on exactly $1 / n$ of the target-present trials (where $n=$ display size), so subjects could not use uniqueness as a reliable cue for target search. These two constraints required us to have slightly fewer Display Size 7 trials than Display Size 3 or 5 trials.

Procedure. The trial events were quite similar to those of Experiment 1 with allowances made for the new display sizes. In the onset condition, the timing of events was the same as in Experiment 1 , but each trial began with six figure eights displayed at the vertices of a hexagon prior to the presentation of the letter stimuli. For Display Size 3, four of these figure eights completely disappeared and some segments were removed from the remaining two to reveal two letters; a third letter appeared simultaneously via sudden onset to create the three letters of that display size. For Display Size 5, two figure eights disappeared, four had segments removed, and a single letter appeared abruptly. For Display Size 7, all six figure eights had some of the segments removed and a single letter appeared abruptly. All of the display events (i.e., segment removal and letter appearance) occurred simultaneously on each trial.

For the intensity and color conditions, the timing of events was as follows: A target letter appeared in the center of the screen for $500 \mathrm{msec}$ followed by a short blank interval of $250 \mathrm{msec}$ and then a fixation cross in the center for $500 \mathrm{msec}$. This was followed by the display of letters.

As before, we emphasized to the subjects in their instructions that the unique item in each display was as likely or as unlikely to be the target as any other item. Standard RT speed and accuracy instructions were also provided.

\section{Results}

The RTs for each condition are displayed in Figure 2, Panels A, B, and C. The error rates are presented in Table 4.

An analysis of variance of the onset condition showed what is obvious in Figure 2A. There is a reliable effect of trial type $[F(2,14)=38.5]$, of display size $[F(2,14)$ $=21.7]$, and of the interaction of these factors $[F(4,28)$ $=6.1]$. The slope of the function for target present and unique is $3.6 \mathrm{msec}$ per item, which is smaller, although
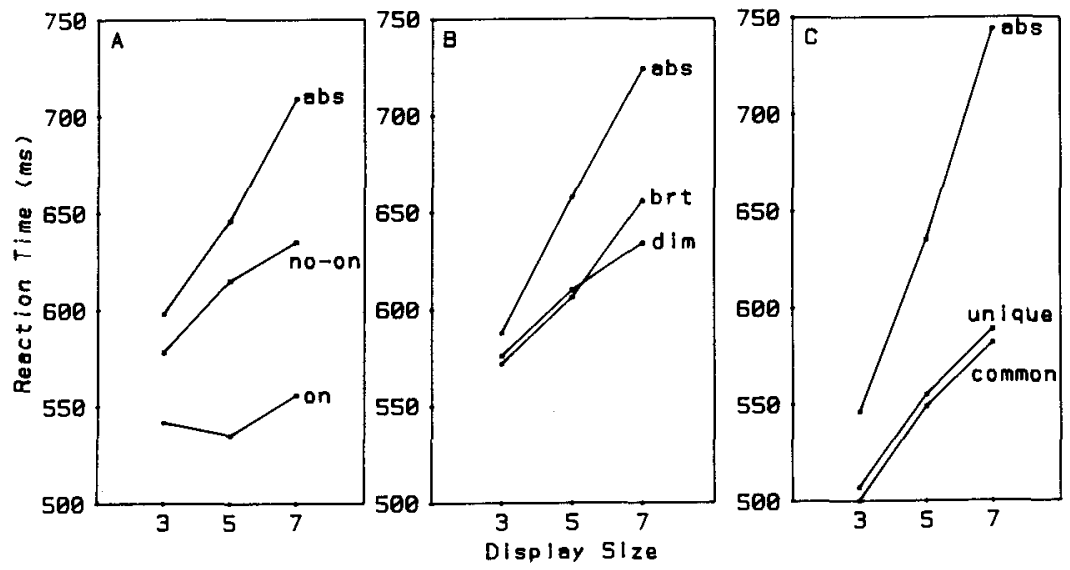

Figure 2. Mean reaction time for present-unique, present-nonunique, and absent trials of Experiment 2 as a function of display size in the onset (Panel $A$ ), intensity (Panel B), and color (Panel C) conditions. on = present-onset; no-on = present-no-onset; abs = absent; brt $=$ present-bright; dim = present-dim; common = present-common color; unique = present-unique color. 
Table 4

Error Rates (Percent) by Condition, Trial Type, and Display Size (3, 5, or 7): Experiment 2

\begin{tabular}{|c|c|c|c|c|c|c|c|c|c|}
\hline \multirow[b]{2}{*}{ Condition } & \multicolumn{3}{|c|}{ Present-Unique } & \multicolumn{3}{|c|}{ Present-Nonunique } & \multicolumn{3}{|c|}{ Absent } \\
\hline & 3 & 5 & 7 & 3 & 5 & 7 & 3 & 5 & 7 \\
\hline Ons & 7.0 & 8.4 & 6 & 10.5 & 11.9 & 17 & 3.7 & 3.9 & 7.6 \\
\hline Intensity & 8.3 & 8.1 & 8.0 & 8.3 & 8.1 & 10.0 & 4.4 & 5.8 & 7.7 \\
\hline Color & 8.9 & 14.8 & 15.3 & 6.3 & 7.7 & 8.0 & 4.4 & 4.0 & 7.2 \\
\hline
\end{tabular}

not quite reliably so, than the slope of the function for nonunique targets $[14.1 \mathrm{msec}$ per target, $t(7)=2.19$, $.05<p<.1]$.

Analysis of the intensity condition data (Figure 2B) also revealed reliable effects of trial type and display size and their interaction $[F(2,14)=10.7, F(2,14)=47.2$, and $F(4,28)=4.9$, respectively]. However, the slopes of the function for unique and nonunique targets-20.6 msec per item and $14.4 \mathrm{msec}$ per item-were not different statistically $[t(7)=-1.0]$.

Finally, analysis of the color condition also showed reliable effects of the two factors and their interaction $[F(2,14)=22.8, F(2,14)=25.2$, and $F(4,20)=9.0$, respectively]. Again, however, the slope difference for the two target-present functions- $-20.2 \mathrm{msec}$ per item and $22.2 \mathrm{msec}$ per item-was not reliable $[t(7)=0.33]$.

As shown in Table 4, the error rates in this experiment were larger than those of Experiment 1 . This is not particularly surprising, given the larger display sizes of the present experiment. Again, error rates generally increased with display size, and a bias toward negative responses was evident. No suggestion of a significant speedaccuracy tradeoff is apparent.

The final analysis concerns the difference in overall RT between the onset condition and the other two conditions found in Experiment 1. The mean overall RTs in the present experiment were 602,625 , and $578 \mathrm{msec}$ for the onset, intensity, and color conditions, respectively. Paired $t$ tests revealed no reliable differences between the onset condition and the other two conditions $[t(14)=0.69$ for the intensity condition comparison and $t(14)=0.65$ for the color condition comparison]. The difference shown in Experiment 1 was evidently due to some factors particular to that experiment, such as subject selection effects, that are not general to the stimulus conditions under investigation.

\section{Discussion}

An inspection of Figure 2 suggests that the pattern of model fits we observed in Experiment 1 was upheld for these data as well. The model fits are provided in Table 5, together with the observed data. The capture model accounts for $98.7 \%, 50.5 \%$, and $63.6 \%$ of the variance in the onset, intensity, and color conditions, respectively. By contrast, the SST model accounts for $71.7 \%, 98.8 \%$, and $99.1 \%$ of the variance in these same conditions. Plainly, the capture model accounts well for the data from the onset condition, while the SST model better accounts for the other two conditions. These fits show once again that uniqueness of a stimulus item in a display is not by itself sufficient for attentional capture. The nature of the uniqueness is critical. Items exhibiting abrupt onset are capable of attracting attention, whereas color or intensity differences evidently are not.

One might ask how this can be so in the face of accumulated evidence from visual search studies about the effect of stimulus differences, such as form, color, texture, and the like. Beginning with studies such as those of Eriksen (1952, 1953) and Green and Anderson (1956), many investigators have established that a target differing, for example, in color from other items in a display is detected much more rapidly than a target that is not so defined. In the most recent demonstrations of this effect, Treisman and her colleagues (e.g., Treisman \& Gelade, 1980) attributed this improved search performance to the rapid detection of activity in a feature map corresponding to the unique attribute. How is it that these many previous studies have found a selective effect with color and other stimulus features, while we did not?

The answer lies in an important difference between our procedure and previous ones, a difference that is at the heart of our experiments. In previous experiments, sub-

Table 5

Observed and Predicted Mean Reaction Times for Capture and SST Models: Experiment 2

\begin{tabular}{|c|c|c|c|c|c|c|c|c|c|c|}
\hline \multirow[b]{3}{*}{ Trial Type } & \multirow{3}{*}{$\begin{array}{l}\text { Display } \\
\text { Size }\end{array}$} & \multicolumn{3}{|c|}{ Onset Condition } & \multicolumn{3}{|c|}{ Intensity Condition } & \multicolumn{3}{|c|}{ Color Condition } \\
\hline & & \multirow[b]{2}{*}{ Observed } & \multicolumn{2}{|c|}{ Predicted } & \multirow[b]{2}{*}{ Observed } & \multicolumn{2}{|c|}{ Predicted } & \multirow[b]{2}{*}{ Observed } & \multicolumn{2}{|c|}{ Predicted } \\
\hline & & & Capture & SST & & Capture & SST & & $\overline{\text { Capture }}$ & SST \\
\hline Present-Unique & $\begin{array}{l}3 \\
5 \\
7\end{array}$ & $\begin{array}{l}542 \\
535 \\
556\end{array}$ & $\begin{array}{l}543 \\
543 \\
543\end{array}$ & $\begin{array}{l}552 \\
577 \\
601\end{array}$ & $\begin{array}{l}572 \\
606 \\
656\end{array}$ & $\begin{array}{l}588 \\
588 \\
588\end{array}$ & $\begin{array}{l}574 \\
609 \\
643\end{array}$ & $\begin{array}{l}507 \\
555 \\
589\end{array}$ & $\begin{array}{l}516 \\
516 \\
516\end{array}$ & $\begin{array}{l}497 \\
545 \\
592\end{array}$ \\
\hline Present-Nonunique & $\begin{array}{l}3 \\
5 \\
7\end{array}$ & $\begin{array}{l}578 \\
615 \\
635\end{array}$ & $\begin{array}{l}583 \\
610 \\
637\end{array}$ & $\begin{array}{l}552 \\
577 \\
601\end{array}$ & $\begin{array}{l}576 \\
610 \\
634\end{array}$ & $\begin{array}{l}613 \\
629 \\
646\end{array}$ & $\begin{array}{l}574 \\
609 \\
643\end{array}$ & $\begin{array}{l}493 \\
549 \\
582\end{array}$ & $\begin{array}{l}551 \\
575 \\
598\end{array}$ & $\begin{array}{l}497 \\
545 \\
592\end{array}$ \\
\hline Absent & $\begin{array}{l}3 \\
5 \\
7\end{array}$ & $\begin{array}{l}598 \\
646 \\
709\end{array}$ & $\begin{array}{l}597 \\
651 \\
705\end{array}$ & $\begin{array}{l}601 \\
651 \\
700\end{array}$ & $\begin{array}{l}588 \\
658 \\
724\end{array}$ & $\begin{array}{l}624 \\
656 \\
689\end{array}$ & $\begin{array}{l}588 \\
656 \\
725\end{array}$ & $\begin{array}{l}546 \\
635 \\
744\end{array}$ & $\begin{array}{l}596 \\
642 \\
689\end{array}$ & $\begin{array}{l}547 \\
642 \\
736\end{array}$ \\
\hline $\begin{array}{l}\text { Percent Variance } \\
\text { Accounted For }\end{array}$ & & & 98.7 & 71.7 & & 50.5 & 98.8 & & 63.6 & 99.1 \\
\hline
\end{tabular}


jects had been provided with a stimulus difference on a dimension such as color that permitted them to use active filtering to select the item that was of importance to their task. In Duncan's (1985) terms, the stimulus difference was a "defining attribute" that distinguished the target from the remaining display characters. Once distinguished in this way, subjects could then either use the mere presence of this item as the basis of their response (if that was the task) or further examine the item to determine its identity. In either case, the stimulus difference provided subjects with a reliable cue, segregating the target from the distractor items in the display. The fact that many of these previous experiments show that search under these circumstances is efficient (indeed, sometimes seemingly conducted in parallel over the array; Egeth et al., 1972) strongly suggests that subjects are able to engage in active filtering on the basis of discriminable differences in physical features. The features that can serve as the basis of such filtering seem to be many in number, and certainly include color.

Our experiments, in contrast, had a very different character. In our tasks, there was a unique item on each and every trial, but this item was not necessarily the target for which the subjects were searching. In fact, the physically odd item was the target on only $1 / n$ of the trials on which a target was present, where $n$ is the number of items in the display. Thus, there was no benefit in singling out the odd item and examining it before examining the other display items. In our experiments, active filtering was not a useful strategy.

Of course, we constructed the task situation with exactly this in mind. The purpose of the experiments was to determine whether unique items-made unique by varying one of three physical characteristics-could seize attention even when there was no benefit accruing to the subject by intentionally allocating attention to them. If so, this would be evidence for a somewhat automatic capture of attention by the unique item. The issue we addressed was whether this sort of capture might be a function of the characteristic that determined uniqueness. Our results suggest that it is.

We argue, then, that the fundamental difference between our procedure and previous ones is the cause of the difference between our results for color and intensity features and previous ones. To illustrate this point more directly, we performed a further experiment in which attention to the unique item was functional, allowing us to compare this condition with a comparable one in Experiment 2 , in which it was not functional.

\section{EXPERIMENT 3}

Because color has been the subject of much of the previous experimentation on the effects of stimulus differences in visual search, we designed Experiment 3 to investigate performance in our task when a uniquely colored item was always the target (when a target was present). This condition was designed to allow direct comparison with the color condition of Experiment 2.

\section{Method}

Subjects. Eight students at the University of Michigan were paid to participate in the experiment. They had normal vision.

Apparatus and Stimuli. The apparatus and stimuli were identical to those used in the color condition of Experiment 2.

Design. The present experiment was modeled on the color condition of Experiment 2. There were only two types of trials, however, by nature of the definition of the condition. Half of the trials contained a target; this target item was always colored red and embedded among other items, all of which were green. The number of items varied, depending on the display size $(3,5$, or 7). The other half of the trials also contained one red item among green ones, but the target was absent. Thus, the subjects had only to examine the red item in each display to determine whether the target was present in that display.

The subjects completed six blocks of 90 trials each. In each block, there were 15 trials in each of the six cells of the design. The six cells were created by crossing trial type (present and absent) with display size $(3,5$, and 7$)$.

Procedure. The trial-by-trial procedure was identical to that of the color condition of Experiment 2. The major new feature of this experiment was that the subjects were told that the red item in each display was the only item that could be the target if a target was present. Thus, it was to the subjects' advantage to attend particularly to this item in their search.

\section{Results}

There were two types of trials in this experiment-target present and target absent-and the reaction times for these trials are plotted as a function of display size in Figure 3A. The error rates for these trials are shown in Table 6. Figure 3B includes the present-unique and absent trials from the color condition of Experiment 2 for comparison with the data of the present experiment.

An analysis of variance of the data in Figure 3A shows that the negative trials yielded longer RTs than the positive trials $[F(1,7)=17.9]$, and that there is an only marginally significant effect of display size on these times $[F(2,14)=3.45, p=.06]$. The interaction between these factors is not reliable $[F(2,14)=0.79]$. The slope of the function for positive trials is $11.5 \mathrm{msec}$ per item, and that for negative trials is $19.6 \mathrm{msec}$ per item; these slopes do not differ significantly $[t(7)=0.75]$.

\section{Discussion}

An inspection of Figure 3 reveals significantly different patterns of RT in the two experiments. First, RT was generally faster in Experiment 3 (Panel A) than in the color condition of Experiment 2 (Panel B). Second, the

Table 6

Error Rates (Percent) for Each Trial Type and Display Size: Experiment 3

\begin{tabular}{lccc}
\multicolumn{4}{c}{ and Display Size: Experiment 3 } \\
\hline & \multicolumn{3}{c}{ Display Size } \\
Trial Type & 3 & 5 & 7 \\
\hline Present & 3.6 & 4.7 & 4.2 \\
Absent & 2.5 & 3.9 & 2.5 \\
\hline
\end{tabular}



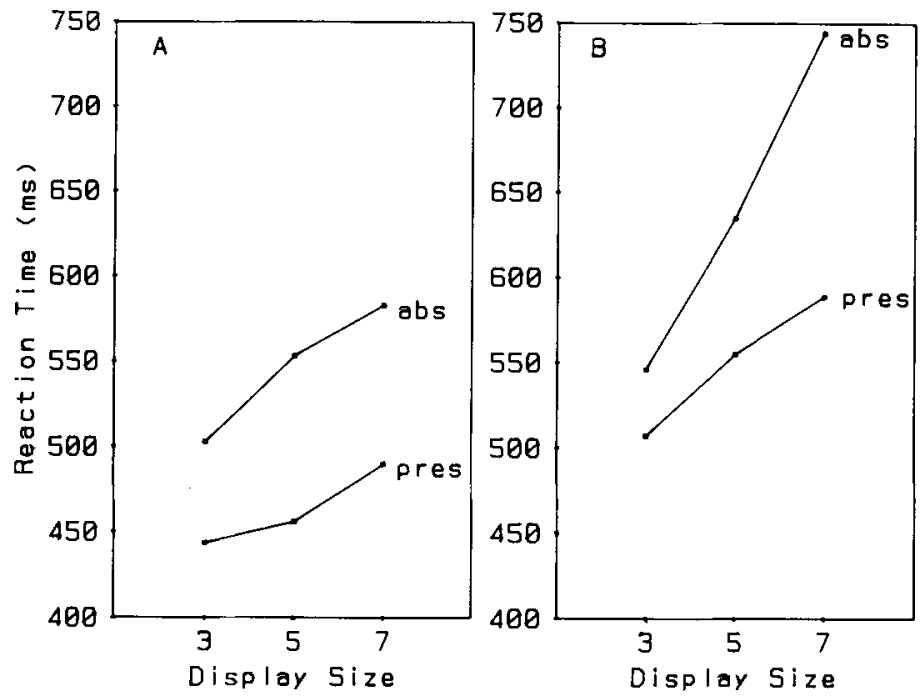

Figure 3. (Panel A) Mean reaction times for present and absent trials in Experiment 3. (Panel B) The present-unique and absent trials of the color condition of Experiment 2. The data in Panel B are identical to the corresponding data in Figure 2C. pres = present; abs $=$ absent.

slopes of the display size functions were much shallower in Experiment 3 (11.5 and $19.6 \mathrm{msec}$ per comparison for present and absent functions, respectively) than in Experiment 2 (20.5 and $49.5 \mathrm{msec}$ per comparison, for the same two conditions, respectively). Finally, the ratio of the slope from the target-absent condition to the slope for the target-present condition was larger in Experiment 2 $(2.4: 1)$ than in Experiment $3(1.7: 1)$. All of these factors together suggest that the process underlying performance in Experiment 3 was quite unlike that in the color condition of Experiment 2.

In particular, we suggest that in Experiment 3 the subjects were probably employing a "single-examination" mode of search that worked as follows. At display onset, the subjects immediately directed attentional resources to the item in the display with a unique color (i.e., the red item), perhaps on the basis of the detection of localized activity in a red "feature map" (Treisman \& Gelade, 1980 ). They then identified the unique item and compared it with the target in memory. When a match with the target occurred, a positive response was initiated; for a mismatch, a negative response was initiated. In neither case were any of the other items in the display processed. According to this model, there is predicted to be no effect of increasing display size, and the slope ratio is predicted to be $1: 1$.

The data clearly do not conform strictly to this model: The slopes of both the present and the absent functions are greater than zero, and the slope ratio is greater than $1: 1$. This may be a result of some contribution of SST processing on a small percentage of trials. However, the overall pattern of results (including the lower overall reaction time, the shallower slopes, and a slope ratio closer to $1: 1)$ is more consistent overall with the single- examination model than with the SST model, particularly if we assume that the times needed to identify an item and to perform all the associated cognitive processing (e.g., response preparation) are similar in the two experiments.

Therefore, performance in the color conditions of Experiments 2 and 3, respectively, seems to be mediated by different processes. When subjects cannot rely on the uniqueness of the red item to tell them where the target is, they apparently examine the display items in turn to discover the target (as in the color condition of Experiment 2). When color represents a reliable search cue, however, subjects evidently often focus on it immediately (as in Experiment 3). We conclude from this pattern that uniqueness of color (and, we presume, intensity) is a sufficient condition for active allocation of attention to take place, but it is not sufficient to capture attention. This is in contrast to the capture of attention we have observed with abrupt onset (Experiments 1 and 2).

\section{GENERAL DISCUSSION}

The three experiments reported here demonstrate that attentional capture, as observed by Yantis and Jonides (1984), may be unique to stimuli that exhibit abrupt visual onset, and does not accrue to stimuli that differ from the background in color or intensity. This finding bolsters our earlier hypothesis that abrupt onset may activate visual channels that are particularly sensitive to abrupt change, and that may automatically seize attentional resources when activated.

We were motivated to conduct these experiments by the worry that if any arbitrary stimulus difference resulted in attentional capture, then an explanation of the effect we observed in our earlier work could not rely on the spe- 
cial properties of abrupt onset or of visual channels specialized for their detection. However, since we have established that abrupt onset per se may be necessary for producing attentional capture, explanations incorporating such properties are still viable. In particular, physiological and psychophysical work has suggested that the visual system is particularly sensitive to abrupt stimulus onset (Breitmeyer \& Ganz, 1976; Breitmeyer \& Julesz, 1975; Cleland, Levick, \& Sanderson, 1973; Krumhansl, 1982; Kulikowski \& Tolhurst, 1973; Todd \& Van Gelder, 1979). The present results, together with our earlier experiments (Yantis \& Jonides, 1984), suggest that there may be a link between the mechanism specialized for the detection of onsets and the properties of the visual attention system.

A further result of these experiments concerns the properties of what Treisman and Gelade (1980) have termed disjunctive visual search in the context of their feature integration theory. Treisman and her colleagues have repeatedly observed that the speed and efficiency of visual search depends crucially on the nature of the object searched for. If it is defined by the conjunction of two or more features, search appears to be sequential and relatively slow; however, if the object searched for is defined by a unique feature (e.g., a red object among green ones), search is rapid and efficient. The claim made by the theory is that in the former case, search requires focal attention, while in the latter case, it does not.

One construal of the theory as it stands is that localized activation in a feature map causes attentional resources to be automatically drawn to the source of the activation. Our results suggest instead that disjunctive features may be employed to efficiently filter the items in the display so as to process only those stimuli possessing task-relevant features (as in the present Experiment 3). Apparently, however, disjunctively defined objects, although easily detectable, do not capture attentional resources as abrupt onsets do.

Of course, we have not remotely explored the complete space of stimulus features that might distinguish targets from distractors in visual search. However, we have established that onset can produce attentional capture, whereas two other salient visual features that have frequently produced powerful effects in other visual taskscolor and intensity-cannot. This may eliminate a large class of features that are even less visually salient as candidates for the task of capturing attention. There remain still other features closely related to onset (e.g., flicker ture. Delineating classes of visual features that do or do not produce attentional capture has implications that should not be ignored for the design of complex visual displays.
Of more theoretical interest, of course, are the possible explanations for this effect that may reveal the structure of the subsystems that subserve visual attention allocation. The possible link between onsets, visual channels specialized for their detection, and visual attention needs more exploration. Furthermore, other properties of capture by abrupt onset (in particular, the extent to which such capture may be characterized as truly automatic) need to be established.

\section{REFERENCES}

Bergen, J. R., \& Julesz, B. (1983). Parallel versus serial processing in rapid pattern discrimination. Nature, 303, 696-698.

BReITMEYER, B. G., \& GANZ, L. (1976). Implications of sustained and transient channels for theories of visual pattern masking, saccadic suppression, and information processing. Psychological Review, 83, 1-36.

BREITMEYER, B. G., \& JuLESz, B. (1975). The role of on and off transients in determining the psychophysical spatial frequency response. Vision Research, 15, 411-415.

Cleland, B. G., Levick, W. R., \&anderson, K. J. (1973). Properties of sustained and transient cells in the cat retina. Journal of Physiology, 228, 649-680.

Donderi, D., Z ZLLNICKER, D. (1969). Parallel processing in visual same-different decisions. Perception \& Psychophysics, 5, 197-200.

Duncan, J. (1985). Visual search and visual attention. In M. Posner \& O. Marin (Eds.), Attention and performance XI (pp. 85-106). Hillsdale, NJ: Erlbaum.

EGETH, H., JoniDES, J., \& WALL, S. (1952). Parallel processing of multielement displays. Cognitive Psychology, 3, 674-698.

ERIKSEN, C. W. (1952). Location of objects in a visual display as a function of the number of dimensions on which the objects differ. Journal of Experimental Psychology, 44, 56-60.

ERIKSEN, C. W. (1953). Object location in a complex perceptual field. Journal of Experimental Psychology, 45, 126-132.

Francolini, C. M., \& Egeth, H. E. (1980). On the nonautomaticity of "automatic" activation: Evidence of selective seeing. Perception \& Psychophysics, 27, 331-342.

Green, B. F., \& ANDERson, L. K. (1956). Color coding in a visual search task. Journal of Experimental Psychology, 51, 19-24.

Kahneman, D., \& Henik, A. (1981). Perceptual organization and attention. In M. Kubovy \& J. R. Pomerantz (Eds.), Perceptual organization (pp. 181-211). Hillsdale, NJ: Erlbaum.

KrumhanSL, C. L. (1982). Abrupt changes in visual stimulation enhance processing of form and location information. Perception \& Psychophysics, 32, 511-523.

Kulikowskı, J. J., \& Tolhurst, D. J. (1973). Psychophysical evidence for sustained and transient detectors in human vision. Journal of Physiology, 232, 149-162.

TODD, J. T., \& VAN GELDER, P. (1979). Implications of a sustainedtransient dichotomy for the measurement of human performance. Journal of Experimental Psychology: Human Perception \& Performance, 5, 625-638.

Treisman, A. M., \& Gelade, G. (1980). A feature-integration theory of attention. Cognitive Psychology, 12, 97-136.

YANTIS, S., \& JoNIDES, J. (1984). Abrupt visual onsets and selective attention: Evidence from visual search. Journal of Experimental Psychology: Human Perception \& Performance, 10, 601-621.

(Manuscript received March 31, 1986; revision accepted for publication September 30, 1987.) 